\title{
Unidade de negócio em informação - UNINF: o futuro das bibliotecas universitárias na sociedade do conhecimento
}

Simone Faury Dib

Bibliotecária-REDE SIRIUS/UERJ-Especialista em Inteligência Empresarial e Gestão do Conhecimento - CRIEECOPPE/UFFJ-sclib@ueri.br

Neusa Cardim da Silva

Bibliotecária - REDE SIRIUS/UERJ - Especialista em Organização do Conhecimento para Recuperação da Informação - UMIRIO . ncardims@gmail.com

Apresenta um novo modelo para a Biblioteca Universitária - BU - que propõe a sua reestruturação em unidade de negócio em informação - UNInf, visando a ampliar seu foco de atuação, adotando uma postura dinâmica e próativa, mantendo, contudo, o objetivo principal: apoiar as atividades de ensino, pesquisa e extensão da universidade. Mostra os resultados de análises estratégicas que comprovam a necessidade dessa mudança, tendo por base os fatos e eventos portadores de futuro, na avaliação das condições de mercado por meio da matriz SWOT - Strenghs, Weaknesses, Opportunities, Threats e no modelo das cinco forças de Porter adaptado para o setor de serviços da instituição estudada, no caso, as bibliotecas universitárias, que não têm fins lucrativos. Apresenta o aporte teórico que norteou o desenvolvimento do modelo da UNInf, criado com base no modelo dos capitais do conhecimento elaborado pelo Centro de Referência em Inteligência Empresarial - CRIE/ COPPE/NFRJ-. Descreve as premissas básicas do modelo e a organização da UNInf de acordo com os capitais de relacionamento, estrutural, intelectual e ambiental.

Palavras-chave: Unidade de negócio em informação; Biblioteca universitária; Gestão do conhecimento; Mudança organizacional. 


\section{Introdução}

As mudanças decorrentes do surgimento da sociedade do conhecimento alteraram as formas de produção de bens e serviços. Nesta nova economia em que o trabalho intelectual e as habilidades das pessoas são especialmente valorizados, o ser humano assume papel fundamental na medida em que é o único elemento capaz de assimilar a informação, desenvolver sua inteligência e compartilhar suas idéias e experiências. Assim, para garantirem a continuidade de seu negócio, as organizações foram impelidas a investir no capital humano, uma vez que o conhecimento tornou-se recurso econômico vital para a sua sobrevivência e competitividade, e o valor dos produtos e serviços passou a depender do grau de inovação, tecnologia e inteligência a eles agregados.

Neste cenário, as universidades e as suas BU's são estratégicas, pois contribuem para aumentar a capacidade das nações de gerar conhecimento e convertê-lo em vantagens competitivas, o que representa riqueza e crescimento.

Segundo Cunha (2000, p. 87)

... à medida que um povo educado e com conhecimento se transforma no elemento-chave da prosperidade, segurança e bem-estar social, a universidade, nessa era de transformações rápidas, destaca-se como uma das mais importantes instituições de nosso tempo.

Dentro desta perspectiva, é inegável a atuação das universidades em benefício da sociedade, principalmente porque visam a formar e capacitar pessoas, a incentivar a produção, o registro do conhecimento e a apoiar o desenvolvimento de pesquisas e as atividades de extensão, fortalecendo o país como um todo.

Da mesma forma, as bibliotecas universitárias, ao apoiarem as atividades de ensino, pesquisa e extensão das universidades, têm papel preponderante no desenvolvimento da sociedade, pois são mediadoras no processo de geração e produção do conhecimento. Contudo, essas bibliotecas, principalmente quando públicas, têm limitações que as impedem de atuarem plenamente, sejam elas referentes a pessoal, a recursos materiais e financeiros ou a infra-estrutura.

Segundo Heemann, Costa e Matias (2000, p. 7), o modelo usual da maioria desse tipo de biblioteca é

o de não possuir estratégias próprias, e agir em função das demandas, muitas vezes desorganizadas, provenientes dos diversos grupos existentes dentro da universidade. Esta falta de identidade faz diferença no reconhecimento da biblioteca como órgão no mesmo nível de importância e status que os demais órgãos da universidade.

Para combater tal inércia e fortalecer sua imagem, a biblioteca universitária precisa se renovar, atuando de acordo com práticas gerenciais modernas e monitorando, constantemente, o ambiente em que está inserida.

Cunha (2000, p. 88) afirma que os próximos anos serão um período de significativas mudanças, em que tanto as universidades quanto as bibliotecas universitárias deverão enfrentar os desafios e aproveitar as oportunidades. 
Para o autor

... no caso da biblioteca universitária, é necessário examinar as enormes possibilidades do futuro e entender que o desafio mais crítico será remover os obstáculos que a impedem de responder às necessidades de uma clientela em mudança, transformar os processos e estruturas administrativas que caducaram e questionar premissas existentes. Aquela biblioteca que der um passo nesse processo de mudança irá renascer...

Assim, o momento é propício para que as bibliotecas universitárias adotem uma postura dinâmica e pró-ativa.

A idéia de desenvolver um novo modelo para as BU's, transformando-as em unidades de negócio em informação - UNInf -, surgiu da necessidade de atender a um nicho de mercado que demanda agilidade e customização e da visão de que as bibliotecas podem gerar recursos, não dependendo somente dos parcos investimentos recebidos. Para tanto, apresentam-se aqui os pressupostos e diretrizes do modelo da UNInf', com o propósito de que seja um instrumento útil no processo de mudança das bibliotecas universitárias.

\section{Análise estratégica das bibliotecas universitárias: o primeiro passo para a elaboração do novo modelo de negócio}

O desenvolvimento do modelo da UNInf foi precedido de análises estratégicas que procuraram mapear o ambiente interno das BU's e identificar, no ambiente externo, as oportunidades e demandas potenciais que serviriam de parâmetro para verificar a viabilidade de implantação do novo modelo, a saber:

a) análise empírica de fatos e eventos portadores de futuro que poderiam influenciar as bibliotecas universitárias;

b) avaliação das condições do mercado por meio da utilização da matriz SWOT-Strenghs, Weaknesses, Opportunities, Threats em que foram identificadas como:

- potencialidades (strenghs) - as características positivas das bibliotecas universitárias, tanto sob a sua ótica interna, quanto sob o ponto de vista de seus usuários;

- fraquezas (weaknesses) - as deficiências internas existentes nas bibliotecas universitárias que prejudicam sua eficiência operacional e sua imagem diante do público-alvo;

' Este artigo originou-se do projeto Um novo modelo de negócio para bibliotecas universitárias, apresentado à COPPE/NFR, como parte dos requisitos necessários para a obtenção do grau de Especialista em Inteligência Empresarial e Gestão do Conhecimento.

- oportunidades (opportunities) - as condições externas às bibliotecas universitárias que podem contribuir para o êxito de seus objetivos; 
- ameaças (threats) - as condições do ambiente externo que podem prejudicar a concretização da missão da biblioteca universitária.

c) utilização do modelo das cinco forças competitivas de Porter, adaptado para o setor de serviços, em função do tipo de instituição analisada, as bibliotecas universitárias, que não têm fins lucrativos.

Os estudos acima citados ratificaram a experiência: os problemas econômicos enfrentados pelo país e, em conseqüência, pelas universidades, sejam elas públicas ou privadas, afetam diretamente as BU's, uma vez que essas instituições dependem de investimentos financeiros das universidades a que estão ligadas e do governo, ficando sua sobrevivência restrita aos parcos recursos recebidos destes órgãos. Em alguns casos, devido ao empenho dos profissionais que nelas atuam, projetos são realizados e aprovados por instituições que patrocinam sua execução. No entanto, são ações isoladas que não representam a realidade das BU's. Ao analisar este cenário, contatou-se a necessidade de essas bibliotecas buscarem alternativas efetivas para a captação de recursos que viabilizem a implementação de ações que visem a melhorias (infra-estrutura, capacitação de seus funcionários etc.) e otimizem o seu funcionamento.

Outro ponto importante verificado foi a existência de uma demanda reprimida por produtos e serviços customizados e com alto valor agregado, não atendida satisfatoriamente, e que se constitui em um nicho de mercado que requer investimentos imediatos. Atender a essa clientela traria diversas vantagens às BU's, entre elas, aporte financeiro, uma vez que informações personalizadas, analisadas por especialistas e preparadas para subsidiarem a tomada de decisão são passíveis de comercialização.

Diante do exposto, verifica-se que o momento atual é propício para a inserção das BU's nesse novo mercado, considerando-se também que entre elas não há concorrência, no sentido mercadológico, de forma que a rivalidade no setor é pouco significativa. Aliado a isto, estas instituições possuem uma estrutura que privilegia a organização da informação, facilitando sua recuperação e disseminação; contam com a experiência dos bibliotecários, profissionais especialistas no gerenciamento de estoques de informação e estão inseridas no ambiente universitário, onde há um contato direto com especialistas (professores, por exemplo), o que favorece o esclarecimento de questões relativas a diversas áreas do conhecimento.

No entanto, para que se tenha sucesso nesse novo empreendimento, não basta apenas utilizar as potencialidades das BU's, é imprescindível que, aliada a isto, seja feita uma revisão em sua estrutura organizacional e em sua forma de atuação, permitindo a adoção de um modelo mais flexível e dinâmico, capaz de transformar muitas de suas fraquezas em pontos fortes, reduzindo assim os riscos impostos pelas ameaças do ambiente externo. 


\section{Unidade de negócio em informação - UNInf: o modelo}

\subsection{Aporte teórico}

modelo da UNInf foi desenvolvido tendo por base o modelo dos capitais do conhecimento, elaborado pelo Centro de Referência em Inteligência Empresarial - CRIE - que pertence à COPPE/NFRJ.

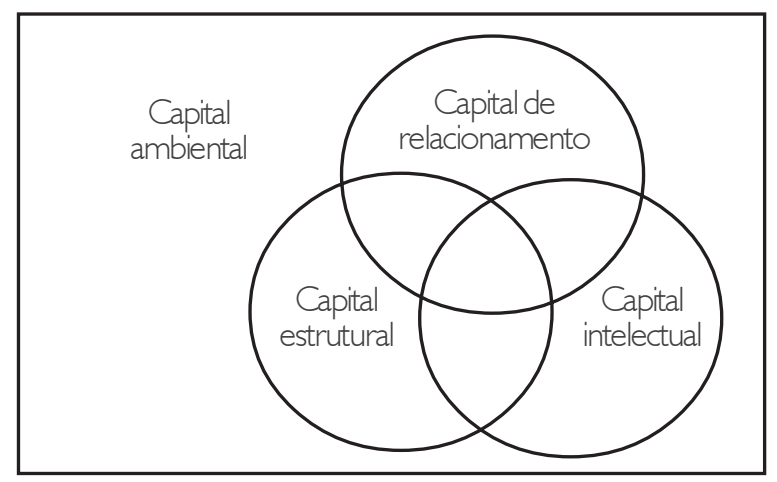

FIGURA I - Modelo dos capitais do conhecimento. Fonte: Cavalcanti, Gomes \& Pereira, 200 I , p. 56.

Segundo Cavalcanti, Gomes e Pereira (200 I), esses capitais devem ser considerados e monitorados, visando a excelência da gestão do conhecimento na organização. São eles:

- $\quad$ capital ambiental é definido como o conjunto de fatores que descrevem o ambiente onde a organização está inserida. São fatores expressos pelo conjunto das características sócioeconômicas da região (nível de escolaridade, distribuição de renda, taxa de natalidade etc.), pelos aspectos legais, valores éticos e culturais (por exemplo, o empreendedorismo), pelos aspectos governamentais (grau de participação do governo na economia, estabilidade política) e pelos aspectos financeiros, como o nível da taxa de juros e a existência de mecanismos adequados de financiamento à produção. [...]

- $\quad$ capital estrutural pode ser definido como [... ] a infra-estrutura necessária para fazer a empresa funcionar. Faz parte ainda do capital estrutural a cultura da organização [...]

- $\bigcirc$ conceito capital intelectual refere-se tanto à capacidade, à habilidade e à experiência quanto ao conhecimento formal das pessoas que integram uma organização. $\bigcirc$ capital intelectual é um ativo intangível que pertence ao próprio indivíduo, mas que pode ser utilizado pela empresa para gerar lucro ou aumentar seu prestígio e reconhecimento social. [...]

- $\bigcirc$ capital de relacionamento [...] é definido como a rede de relacionamentos de uma organização com clientes, fornecedores e parceiros. (Cavalcanti, Gomes e Pereira, 200 I , p. 55) 


\subsection{Pressupostos básicos}

A seguir serão apresentadas informações sobre o novo modelo de negócio, fundamentais para que seja compreendido:

a) A transformação da BU em UNInf não representa simplesmente uma troca de nome, mas o seu reposicionamento estratégico, que permitirá a sua inserção no mercado como uma instituição geradora de recursos;

b) A UNInf será orientada pelas seguintes vertentes estratégicas:

- Negócio de atuação - disseminar a informação de forma rápida, confiável e eficaz.

- $\quad$ Visão de futuro - ser um referencial de excelência na oferta de produtos e serviços informacionais com alto valor agregado.

- Missão genérica - selecionar, captar, processar, armazenar e divulgar informações com valor agregado, em tempo hábil, contribuindo para a geração do conhecimento.

- Objetivos estratégicos - apoiar as atividades de ensino, pesquisa e extensão das universidades; prestar serviços de assessoria técnica (consultoria), de forma a ampliar seu foco de atuação e responder a uma demanda latente por informações customizadas; gerar receita pela comercialização de produtos e serviços informacionais, com valor percebido pelo cliente, e pela execução de projetos.

c) A mudança para esse novo modelo de negócio não implica a descontinuidade de investimentos financeiros por parte das universidades e do governo nas BU's. Contudo, a longo prazo, o volume desses investimentos poderá ser minimizado, tendo em vista a atuação efetiva das unidades de negócio em informação UNInf;

d) A UNInf poderá ser especializada em uma ou mais áreas do conhecimento, desde que seja mantida a eficácia do seu funcionamento;

e) Todos os usuários da BU poderão ser clientes da UNInf;

f) Os produtos e serviços customizados (personalizados) poderão ser comercializados em função do valor percebido pelo cliente. Já os serviços básicos como consulta ao acervo, empréstimo domiciliar e entre bibliotecas, devolução e reserva de obras deverão ser oferecidos gratuitamente;

g) $\bigcirc$ modelo deverá ser adaptado ao perfil da instituição que pretender adotá-lo. 


\subsection{Organização da UNInf}

modelo de negócio da UNInf foi desenvolvido da seguinte forma:

FIGURA 2 - Os quatro capitais de uma UNINF

Fonte: baseado em Cavalcanti, Gomes \& Pereira, 200 I, p. 56.

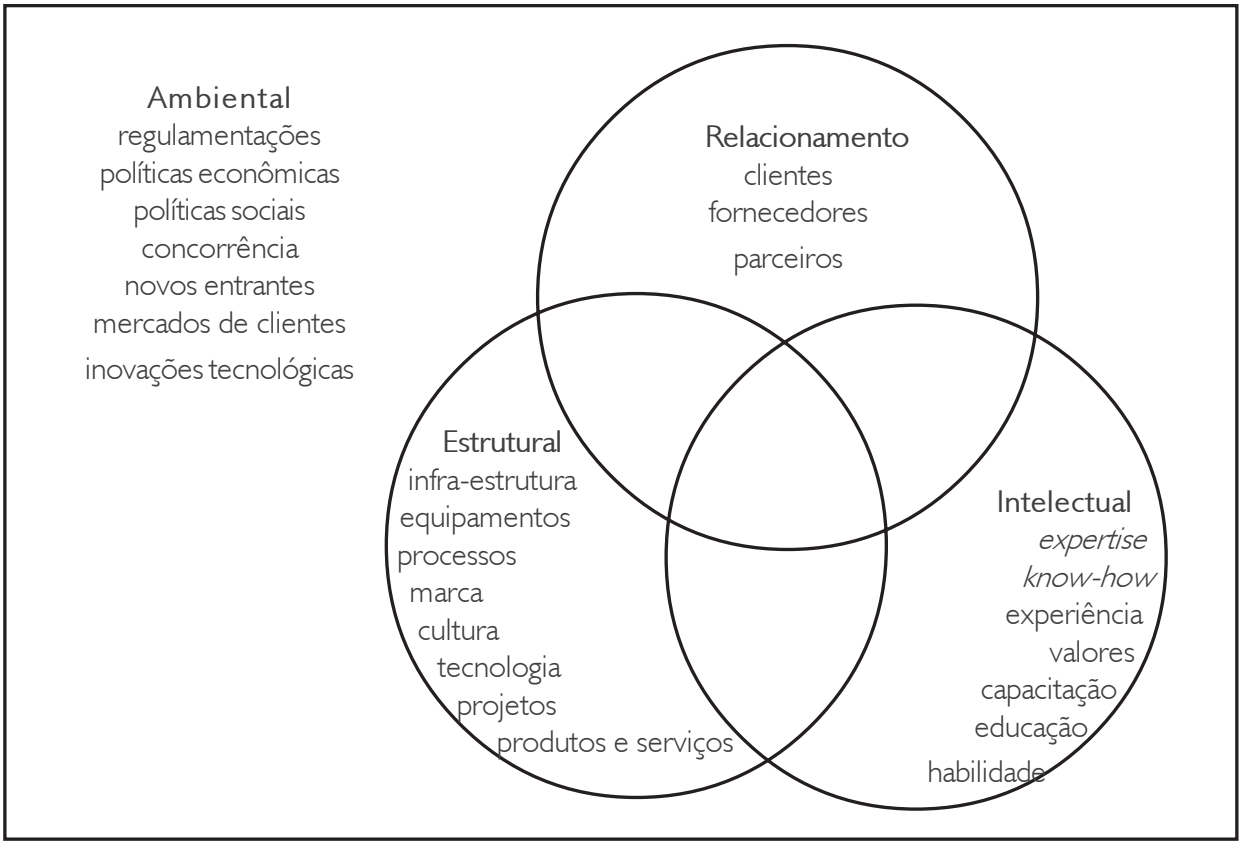

\section{Capital de relacionamento}

○ capital de relacionamento da BU deverá ser ampliado pela UNInf, por meio de ações que fortaleçam as relações existentes e viabilizem novos contatos, favorecendo a construção de uma sólida carteira de clientes, parceiros e fornecedores.

Inserida no ambiente universitário, a UNInf deverá fortalecer sua parceria com todas as unidades e departamentos da universidade mantenedora, estreitando o relacionamento com docentes, profissionais técnico-administrativos e discentes, especialmente os da pós-graduação, uma vez que todos poderão atuar como consultores, prestando serviços de assessoria técnica nos projetos da UNInf.

Profissionais que não pertençam à universidade mantenedora, mas estejam aptos a contribuírem no desenvolvimento de determinado projeto, também poderão ser convidados a prestar consultoria à UNInf.

Outras instituições e, também, empresas poderão ser patrocinadoras e/ou parceiras da UNInf. E, ainda, no que diz respeito a parceiros, é importante destacar a participação do governo que, ao incentivar o desenvolvimento do país, poderá subsidiar as ações da UNInf.

Quanto aos fornecedores, a UNInf deverá fortalecer os vínculos existentes com editoras, distribuidores, autores e empresas de suporte à infra-estrutura (informática, mobiliário, material de escritório etc.), buscando sempre ampliar este relacionamento de forma a garantir que sua estrutura organizacional funcione adequadamente. 
Em relação aos clientes (alunos, professores e funcionários da universidade mantenedora, empresas e instituições, governo e sociedade em geral), a UNInf deverá adotar uma postura pró-ativa, procurando atender às demandas latentes do mercado, criando mecanismos para satisfazer suas necessidades, expectativas e desejos.

\section{Capital estrutural}

Assim como o capital de relacionamento, o capital estrutural existente nas BU's também deverá ser aproveitado e adequado ao novo modelo de negócio.

Este capital engloba infra-estrutura; projetos, processos, produtos e serviços; equipamentos e tecnologia; marca e cultura.

A infra-estrutura da BU deverá ser revista e modificada, se necessário, para dar suporte à nova estrutura organizacional da Unidade, que compreenderá os níveis estratégico, tático e operacional.

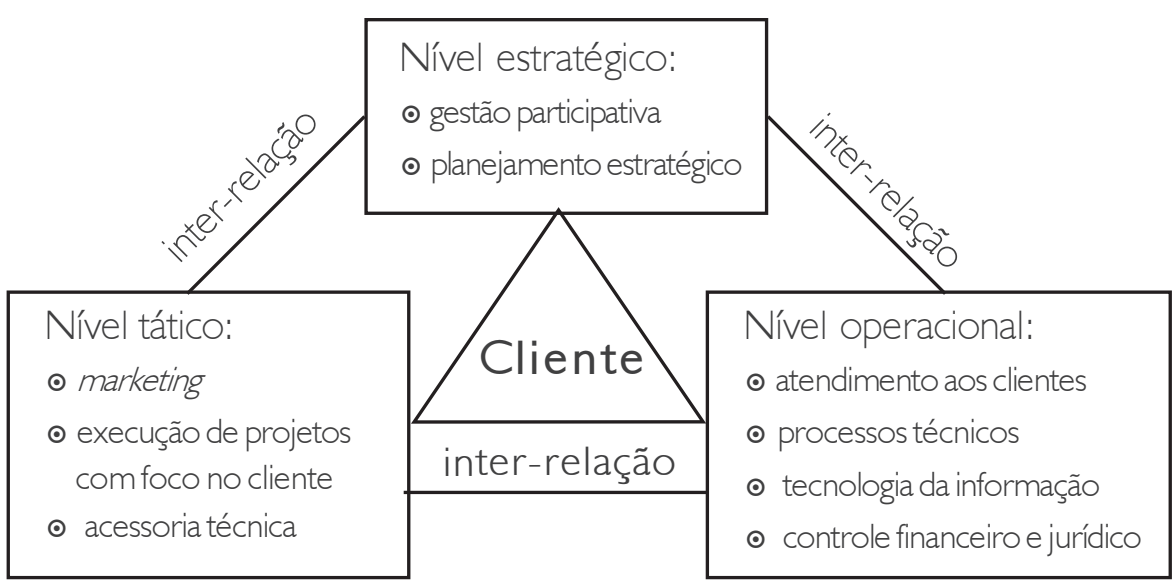

FIGURA 3 - Estrutura organizacional da UNInf

Fonte: Dib, Oliveira \& Soares, 2003, p. 31 .

O nível estratégico contempla a gestão participativa, que favorece a comunicação entre os níveis que compõem a estrutura da UNInf e o feedback das informações, fornecendo subsídios ao planejamento estratégico e à tomada de decisão incentivando, ao mesmo tempo, o comprometimento da equipe.

O nível tático compreende a execução de projetos com foco no cliente, toda a parte relacionada à assessoria técnica e à área de marketing, que terá como objetivos principais divulgar e posicionar a UNInf frente à mantenedora e ao mercado, e colaborar no planejamento de projetos e produtos.

nível operacional, por sua vez, compreende o atendimento aos clientes, os processos técnicos (seleção, aquisição, catalogação, classificação e indexação), a área de tecnologia da informação - que fornecerá suporte técnico à UNInf e participará, quando necessário, de projetos desenvolvidos por ela - , e, finalmente, o controle financeiro e jurídico da unidade.

Com relação aos projetos, eles poderão ter foco externo ou interno. É considerado externo todo projeto que for desenvolvido para atender a solicitação de um determinado cliente, levando em consideração suas necessidades e interesses. Os projetos internos 
serão aqueles direcionados à melhoria da própria UNInf.

Quanto aos processos da unidade, depois de mapeados, devem ser padronizados e documentados (explicitados), por meio de procedimentos, possibilitando, desta forma, que a informação flua por todos os níveis da unidade.

Caberá à UNInf o monitoramento contínuo das necessidades, expectativas e desejos de seus clientes, para que possa definir quais produtos e serviços irá oferecer. Pesquisas de mercado e estudos de usuários são ferramentas que auxiliam o planejamento e o desenvolvimento de novos produtos e serviços.

Para garantir sua atuação efetiva no mercado, é imprescindível que a UNInf monitore os avanços tecnológicos, adquirira novos equipamentos, quando necessário, e faça a manutenção dos já existentes.

Com relação a sua marca, torna-se fundamental o investimento em estratégias que a projetem e a fortaleçam no ambiente interno e externo.

Para dar suporte a essa nova estrutura, é importante rever a cultura organizacional existente nas BU's, enfatizando o envolvimento e comprometimento dos seus profissionais no processo de mudança.

\section{Capital intelectual}

modelo de negócio da UNInf implica reavaliar o perfil dos profissionais que atuam na BU, pois a operacionalização desse tipo de negócio requer uma visão holística do ambiente interno e externo à unidade. Dessa forma, a UNInf demandará competências não apenas dos bibliotecários, mas também de profissionais com experiências em outras áreas, como finanças e estudos de mercado. Todos deverão trabalhar em equipe, mantendo uma relação de sinergia, tornando o ambiente saudável e produtivo.

Devido a sua importância para o sucesso deste empreendimento, o capital intelectual deve ser trabalhado imediatamente após a decisão de se implementar uma UNInf. Assim, é fundamental mapear as competências existentes e as requeridas, identificando os gaps e elaborando um plano de ação que contemple informações como: treinamentos necessários, a real necessidade de contratação de novos profissionais etc. Embora estes estudos devam ser desenvolvidos tendo por base as especificidades da BU que adotará o novo modelo e de sua mantenedora, pode-se afirmar que qualquer profissional que atuar na UNInf deverá ter um perfil flexível, estando apto a:

- monitorar, constantemente, as mudanças impostas pelos avanços da tecnologia, sendo receptivos a elas;

- $\quad$ desenvolver sua criatividade, adaptando-se às novas demandas informacionais dos clientes;

- ser empreendedor;

- ser habilidoso para lidar com pessoas, tanto colegas de equipe 
quanto clientes;

- flexibilizar processos de trabalho, descentralizando decisões e delegando responsabilidades;

- desenvolver projetos, produtos e serviços com foco no cliente;

- inovar e competir por novos espaços;

- planejar a redução do ciclo de vida dos produtos e serviços para renová-los e adaptá-los de acordo com as necessidades identificadas;

- aprender constantemente (educação continuada).

É mediante o compartilhamento dessas aptidões, competências, habilidades e conhecimentos que se constrói o capital intelectual. Gerenciar esse capital, de forma hábil, torna-se exigência crítica para os gestores contemporâneos e, fator primordial para impulsionar o crescimento da UNInf e por conseguinte, da universidade mantenedora.

\section{Capital ambiental}

As regulamentações, as políticas econômicas e as políticas sociais adotadas pelo governo exercem grande influência nas universidades. Por essa razão, a UNInf deverá monitorar este ambiente e rever, quando necessário, seu planejamento, para que esteja apta a apoiar as atividades de ensino, pesquisa e extensão das universidades.

Outros aspectos que devem ser objeto de atenção da UNInf, constituindo-se em oportunidades ou ameaças ao negócio, são relativos aos novos entrantes - possíveis competidores -, às tendências do mercado, às demandas dos clientes e a evolução da concorrência competidores já estabelecidos.

Além disso, é de fundamental importância acompanhar os avanços tecnológicos, identificando quais tecnologias poderão auxiliar o desenvolvimento da UNInf, tanto no que se refere à infra-estrutura e equipamentos, quanto à qualidade de trabalho de seus profissionais.

monitoramento do capital ambiental pode ser feito de diversas maneiras, desde que seja uma tarefa contínua e precisa, pois os resultados das análises influenciarão diretamente os demais capitais do conhecimento.

\section{Consideraç̃ões finais}

Após o estudo realizado, acredita-se que aquelas BU's que investirem neste modelo de negócio tornar-se-ão instituições dinâmicas, inovadoras, competitivas e amplamente reconhecidas, servindo de instrumento para aproximar a pesquisa acadêmica do expertise mercadológico.

No entanto, modificar os paradigmas adotados por uma BU não é uma tarefa simples, principalmente porque ela se insere na cultura organizacional 
de sua universidade mantenedora. Por essa razão, é imprescindível que principalmente os dirigentes dessas instituições acreditem no novo modelo e decidam investir nele, pois, dentre os benefícios recebidos com sua implantação, encontram-se a projeção e fortalecimento da marca da universidade no mercado; a expansão do seu capital de relacionamento, favorecendo as relações de parceria; o crescimento da área de pesquisa; o aperfeiçoamento profissional de professores, mestrandos e doutorandos (educação continuada) que, ao participarem dos projetos da UNInf, contribuirão para a disseminação do conhecimento entre a comunidade acadêmica.

Assim como as universidades, os clientes serão beneficiados com produtos e serviços customizados e com alto valor agregado, agilidade no atendimento e atenção direcionada às suas necessidades, expectativas e desejos.

Já os profissionais bibliotecários terão a oportunidade de ampliar o escopo de suas atividades, não se restringindo apenas ao desempenho das tarefas técnicas, o que Ihes permitirá acompanhar e se adequar às mudanças do ambiente externo, possibilitando um aprendizado contínuo.

Espera-se que a implantação deste modelo traga resultados positivos para a área da informação, como o reposicionamento das BU's frente à universidade e à sociedade; a valorização do profissional bibliotecário elemento-chave do modelo, por ser o agente intermediário entre a informação e o cliente -; o exercício efetivo da gestão participativa; o incentivo ao trabalho em equipe bem como a sinergia entre os profissionais.

\section{Information business unit: the future of academic libraries in knowledge society}

Presents a new model for the University Library that proposes its reorganization in Information Business Unit (UN/nf), aiming at the extension of its focus of performance, adopting a dynamic and pro-active position, however keeping its main objective: to support the education, research and extension activities of the university. It shows the results of strategic analyses proving the necessity of this change based on the facts and events carriers of future, on the evaluation of the market conditions through the SWOT matrix - Strenghs, Weaknesses, Opportunities, Threats - and on the model of Porter's five forces, adapted to the services sector of the studied institution type, to wit, the nonprofit University Libraries. It presents the theory that guided the development of the model of the UNInf, created on a knowledge capital models basis, elaborated by Centro de Referência em Inteligência Empresarial - CRIE - that belongs to COPPENFR/. It also describes the basic premises of the model and the organization of the UNInf, according to relationship, structural, intellectual and ambient capitals.

Key-words: Information business unit; Academic library; Knowledge management; Organizational change. 


\section{Referências}

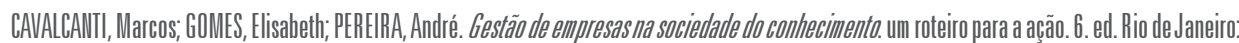
Campus, 2001.170p.

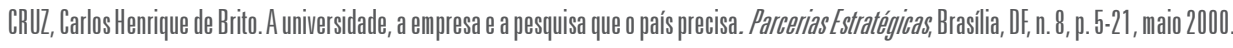

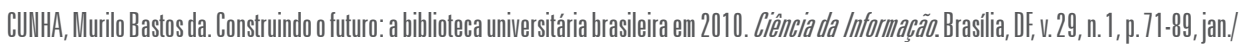
abr. 2000 .

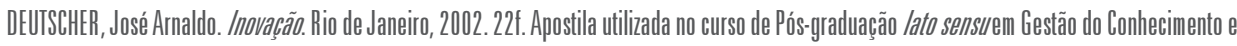
Inteligência Empresarial, ofereecido pelo CRIIE- COPPE/JFrJ.

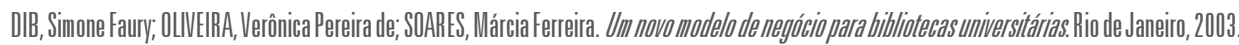

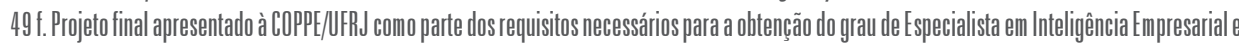
Gestão do Conhecimento.

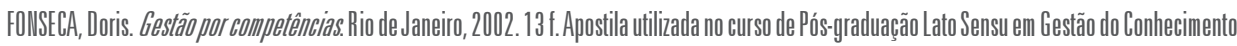
e enteligência Empresarial, oferecido pelo CRIE- COPPE/UFR.

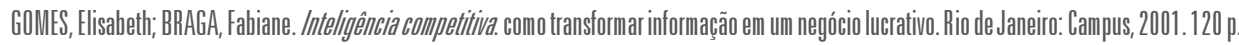

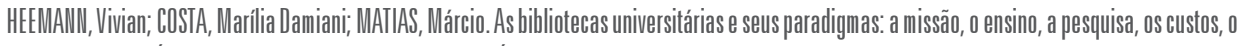

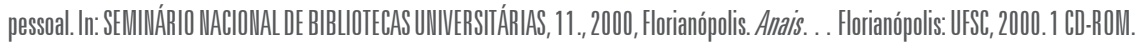

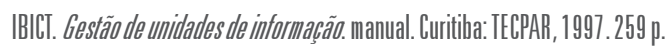

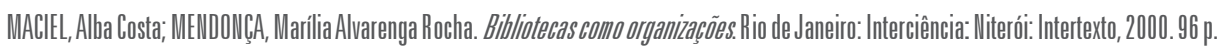

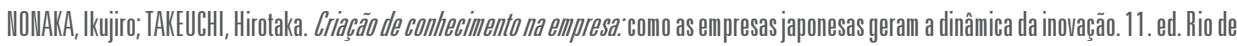
Janeiro: Campus, 1997.

PORTER, Michhal E. Estratáégia commpetitiva. técnicas para análise de indústrias e da concorrência. 7. ed. Rio de Janeiro: Campus, 1991.362 p.

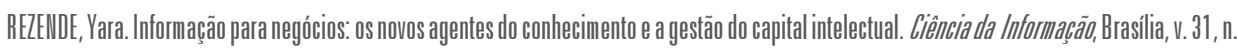
2, p. 120-8, maio/ago. 2002.

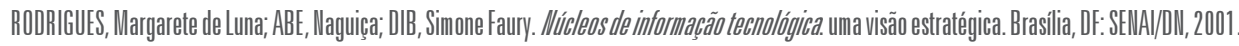
29 p. (Série IT).

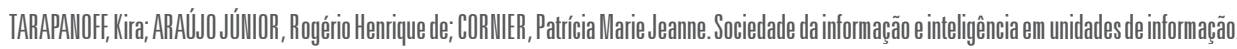

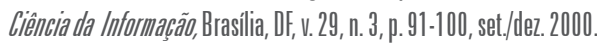

